\title{
The Relationship Between Fetal Hemoglobin and Disease Severity in Children With Sickle Cell Anemia
}

\author{
Daniel J. Odenheimer, Sharada A. Sarnaik, Charles F. Whitten, \\ Donald L. Rucknagel, and Charles F. Sing \\ Department of Human Genetics, University of Michigan, Ann Arbor (D.J.O., \\ D.L.R., C.F.S.) and Comprehensive Sickle Cell Center and Pediatrics, \\ Wayne State University, Detroit (S.A.S., C.F.W.), Michigan
}

\begin{abstract}
A study was conducted in a sample of 140 children with sickle cell anemia to evaluate the relationship between hematological variables $(\% \mathrm{HbF}, \% \mathrm{HbA} 2, \% \mathrm{Hb}$, and mean cell volume) and disease severity. A patient's severity status was determined by whether he/she was hospitalized, had a transfusion, and/or had a pain crisis at 2 evaluation periods; the first was based on a patient's history taken at the initial assessment visit to the Wayne State Comprehensive Sickle Cell Center, and the second was based on a 1-3 year follow-up at the center. Fetal hemoglobin was a strong predictor of a patient's hospitalization and transfusion status. A decrease in $\% \mathrm{HbF}$ of $4.76 \%$ (one $\mathrm{SD}$ of $\% \mathrm{HbF}$ ) was associated with a 3.58 fold (95\% confidence interval, 1.18-7.28) greater odds of being hospitalized both prior to initial assessment and on follow-up, compared to not being hospitalized at either evaluation. Similarly, a decrease in $\% \mathrm{HbF}$ of $4.76 \%$ was associated with a 5.56 fold ( $95 \%$ confidence interval, 1.67-18.96) greater odds of having a transfusion both prior to initial assessment and on follow-up compared to not having a transfusion at either evaluation. Patients who were both hospitalized and transfused at initial assessment and on follow-up $(n=12)$ had a mean $\% \mathrm{HbF}$ of $7.59 \%$, while patients who were not hospitalized or transfused at either evaluation $(\mathrm{n}=19)$ had a mean $\% \mathrm{HbF}$ of $13.61 \%$. Fetal hemoglobin was not a significant predictor of pain crises in this sample of patients. None of the other hematological variables were significant predictors of disease severity in this study. The strong relationship between $\% \mathrm{HbF}$ and disease severity identified in this study suggests that a single \% $\mathrm{HbF}$ measurement may be useful in predicting important aspects of the clinical course of children with sickle cell anemia.
\end{abstract}

Received for publication April 5, 1986; revision received November 13, 1986.

Address reprint requests to Charles F. Sing, Department of Human Genetics, University of Michigan, Ann Arbor, MI 48109-0618. 
Key words: sickle cell anemia, hemoglobin F, red cell predictors

\section{INTRODUCTION}

The clinical course of sickle cell anemia is highly variable, ranging from individuals who experience frequent pain crises, are often hospitalized, and require many transfusions to those who rarely, or never experience these events. The Wayne State Comprehensive Sickle Cell Center has provided an excellent opportunity to evaluate the degree to which the hematological variables predict the frequency of pain crises, hospitalizations, and transfusions. In this study we evaluate the ability of an individual's average level of $\% \mathrm{HbF}, \% \mathrm{HbA}_{2}, \% \mathrm{Hb}$, and $\mathrm{MCV}$ during a 3-year period (1977 to 1980) to predict the occurrence of these 3 measures of severity.

It is well established that the clinical manifestations of sickle cell anemia vary with age. Individuals generally do not display clinical symptoms in the first 6 months of life; the clinical manifestations often become quite severe in early and middle childhood and then may become less severe in adolescence and young adulthood [Warth and Rucknagel, 1983]. Alternatively, some patients do not experience significant symptoms until the third decade. Thus, at any given clinical evaluation, a patient's clinical manifestations of the disease will be highly age dependent. In this study our strategy was to define clinical severity by combining information collected at a patient's first visit to the Sickle Cell Center with data from routine visits that occurred during a 3-year follow-up period. It is expected that combining information on severity from these 2 clinical evaluations will provide a more representative measure of an individual's disease severity than if data from only one time period were considered. We asked in this study whether hematological data collected in the period between these 2 clinical assessments, at initial assessment and during the follow-up period, predict the observed measures of disease severity.

\section{METHODS}

\section{Analytical}

The proportion of $\mathrm{HbF}$ was measured by a radial immunodiffusion assay [Chudwin and Rucknagel, 1975]. HbF was measured by elution from cellulose acetate strips. Total hemoglobin concentration and red cell indices were measured using the Coulter Model S Counter.

\section{Sample}

A description of a large sample of patients $(n=360)$ seen at initial assessment at the Wayne State Comprehensive Sickle Cell Center has been presented elsewhere [Odenheimer et al, 1983]. This sample consisted of children who were first seen at the Sickle Cell Center between October 1973 and October 1980;65\% of the subjects had their initial assessment before January 1976. For the study reported here we selected from this sample 140 individuals who 1) were more than one year old at their initial assessment visit; 2) were never part of a special program that may have affected their hematological or clinical status (eg, transfusion therapy); 3) reported at the initial assessment whether they had ever been hospitalized, transfused, or had a pain crisis as a consequence of sickle cell disease; 4) were evaluated for hematological variables at least once in the period Janury 1977 to January 1980; and 5) were clinically evaluated (number of pain crises, number of hospitalizations, and number 
of transfusions) for a minimum of 1 year during a follow-up period between January 1980 and January 1983. The mean age of the 140 individuals studied here was 5.24 years at their initial assessment and 10.94 years at the midpoint of the 1980 to 1983 follow-up period.

Each patient enrolled in the Sickle Cell Center is scheduled for a routine clinical evaluation every 3 months. For this report we have only considered the clinical assessments between June 1980 and June 1983 as the follow-up period because a more comprehensive clinical evaluation scheme was initiated in 1980. The mean interval between a patient's initial assessment visit to the Sickle Cell Center and the midpoint of the follow-up period was 5.7 years. Although each patient was scheduled to be seen at the Center every 3 months, this routine varied greatly among patients. In the sample of 140 patients considered here, the mean interval between visits was 0.37 years, the average length of time covered by the clinical assessment during the followup period was 1.5 years (range, 1-3), and the average number of evaluations per individual was 4.1 (range, 1-7).

\section{Variables Studied and Statistical Analysis}

At each clinic visit, the patient (or the patient's parents) was asked to report the number of hospitalizations, the number of transfusions (transfusions of more than one unit of blood were considered as a single transfusion), and the number of pain crises of duration greater than $24 \mathrm{hr}$ that occurred since the last routine clinic visit.

Four severity classes were defined for each of the 3 measures of severity (number of pain crises, hospitalizations, and transfusions). The 4 classes were 1) those individuals who had at least one event at both evaluations (eg, individuals who were hospitalized both before enrollment to the Center and on at least one occasion during the follow-up period); 2) those who had the event recorded at the initial assessment as having occurred before enrollment into the study but did not report such an event during the follow-up period; 3) those who reported an event during the follow-up but not at the initial assessment; and 4) those who did not report an event at either evaluation.

Because the ranking of the values of an individual's hematological variables remained relatively stable over time [Odenheimer et al, 1984], an individual's mean value for each measurement during the period considered (January 1977 to January 1980) was taken to represent an individual's hematological status. Linear regression of an individual's mean value on his average age for the period January 1977 to January 1980 was used to correct these data for age variation.

Each severity measure was coded from 0 to 2 , depending on whether an individual had the event at neither the initial assessment nor at the second clinical assessment (0), at either initial assessment or at the second clinical evaluation (1), or at both initial assessment and at the second clinical evaluation (2). The correlation between the 4 severity classes of one measure of severity and the 4 severity classes of a second measure was evaluated by the Goodman-Kruskal Gamma test [Goodman and Kruskal, 1972], a measure of ordered association. The Goodman-Kruskal Gamma varies between -1 and 1 . In general, values close to 1 or -1 indicate a strong monotonic relationship between the variables, and values near zero indicate the lack of a monotonic relationship between the variables.

The association between an individual's hospitalization, transfusion, and pain crisis status at initial assessment and at the clinical assessment of the follow-up period 


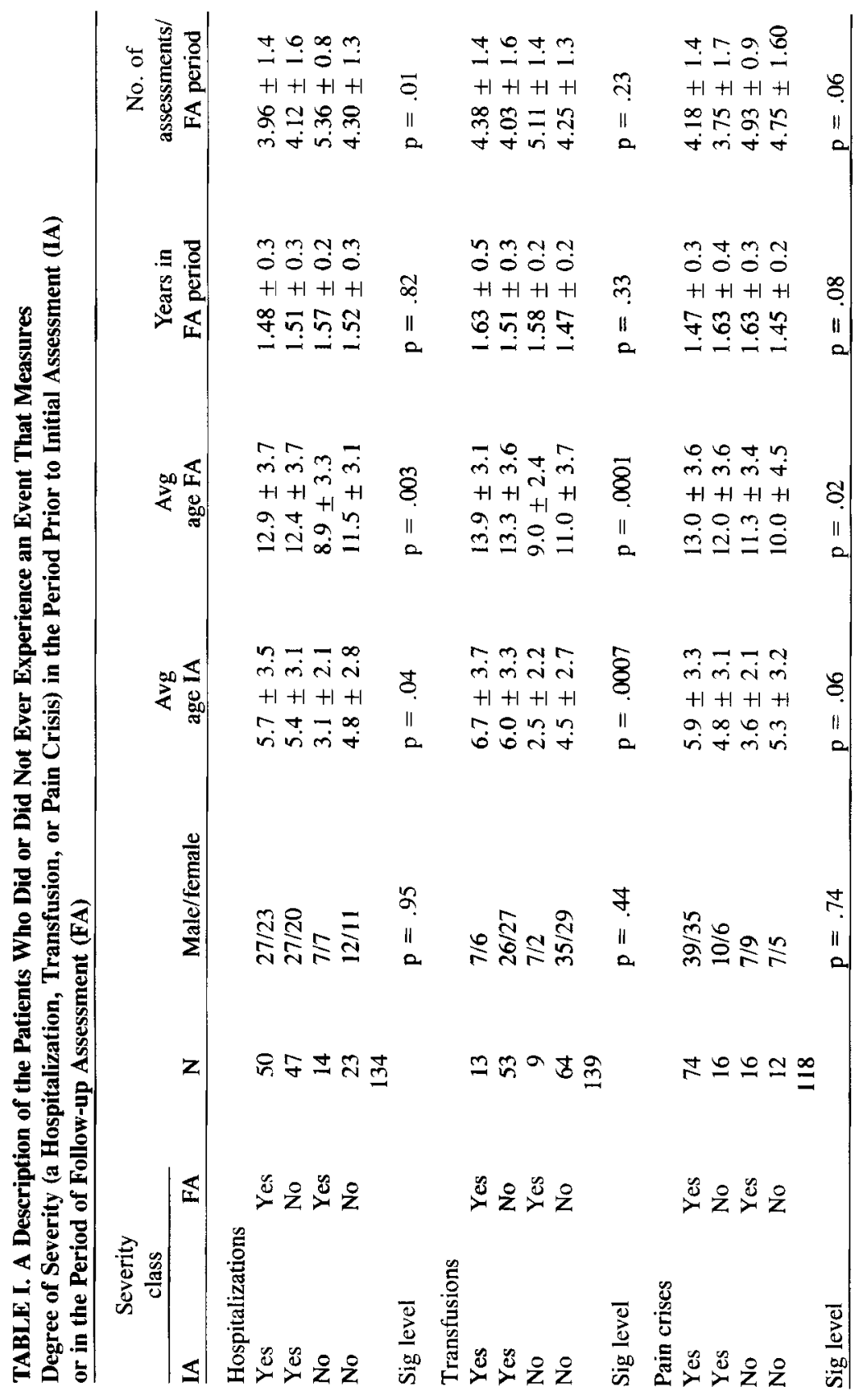


was evaluated using the Kappa statistic [Fleiss, 1981]. Kappa is a measure of the observed excess concordance between an individual's status at initial assessment and at the second clinical assessment, compared to the concordance expected under a hypothesis that these 2 evaluations were independent. Kappa is equal to 1 if the results of the 2 evaluations are in perfect agreement, 0 if the level of agreement is equal to that expected under independence, and $-P_{e} /\left(1-P_{e}\right)$, (where $P_{e}$ is the expected agreement under independence) if the results of the 2 evaluations are in total disagreement.

A stepwise logistic risk function analysis was used to model the relationship between 6 independent variables (age, sex, $\% \mathrm{HbF}, \% \mathrm{HbA}_{2}, \% \mathrm{Hb}$, and $\mathrm{MCV}$ ) and the disease severity measures [Kleinbaum et al, 1982]. The logistic risk function is given by:

$$
\mathrm{P}(\text { Severity class } \mathrm{X})=\exp \left(\mathrm{b}_{\mathrm{o}}+\mathrm{b}_{\mathrm{i}} \mathrm{x}_{\mathrm{i}}\right) /\left(1+\exp \left(\mathrm{b}_{\mathrm{i}} \mathrm{x}_{\mathrm{i}}\right)\right)
$$

where $b_{o}$ is the intercept term and $b_{1} ; \ldots b_{6}$ are the coefficients relating the 6 predictor variables, $\mathrm{X}_{\mathrm{i}}$, and the severity outcome. The vector of parameters $\left(b_{i} \ldots b_{m}\right)$ is estimated using the maximum likelihood approach, and hypothesis tests are based on the likelihood ratio criterion ( $\mathrm{X}=-2$ (lnL(complete model) $\ln ($ reduced model)). For large samples, $\mathrm{X}$ is approximately distributed as a chi square with degrees of freedom equal to the differences in the number of parameters in the full and reduced model. Odds ratios per change in $1 \mathrm{SD}$ of the predictor variables (adjusted for all other variables included in the model) were calculated as $\exp \left(b_{i} x 1\right.$ $\mathrm{SD}$ ), where $b_{\mathrm{i}}$ was the regression coefficient of the ith independent variable being evaluated in the logistic model. At the first step of the analysis, the intercept term $b_{o}$ was included in the logistic model. At each subsequent step, another variable was entered in the model if the significance level of the likelihood ratio test 2 $\ln (\mathrm{L}$ (current model)/L(candidate model)), was less than 0.10 . If more than one variable satisfied this criterion, the combination of variables with the lowest significance level was included in the model, and the selection procedure was repeated. In addition, a variable already included in the model was removed if it no longer significantly predicted disease $(p>0.15)$ when an additional variable was included in the model. Prior to carrying out the logistic regression analysis, the average value during the period from January 1977 to January 1980 of each of the 4 hematological phenotypes considered as independent variables in this analysis was adjusted for the average age of patients during the period.

\section{RESULTS}

A description of the patients stratified by the severity class assigned for each of the 3 severity measures at the initial assessment and for the follow-up period is presented in Table I. Of the 97 patients who had been hospitalized as a consequence of sickle cell disease at least once before enrolling in the center, $50(52 \%)$ were also hospitalized at least once during the period of follow-up, while of the 37 individuals who were not hospitalized before enrolling in the Center, 14 (38\%) were hospitalized at least once during the 3-year follow-up, 1980 to 1983. The Kappa statistic was not significantly different from zero $(0.11 \pm 0.07)$, suggesting that there was only a weak association between the evaluation of an individual's prior hospitalization status at 
TABLE II. Average Levels of Four Age-Adjusted Hematological Variables Measured in the Period Between Initial Assessment (IA) and Follow-up Evaluation (FA) for Each of the Severity Classes*

\begin{tabular}{|c|c|c|c|c|c|c|}
\hline \multicolumn{2}{|c|}{ Severity class } & \multirow[b]{2}{*}{$\mathrm{N}$} & \multirow[b]{2}{*}{$\% \mathrm{HbF}$} & \multirow[b]{2}{*}{$\% \mathrm{HbA}_{2}$} & \multirow[b]{2}{*}{$\% \mathrm{Hb}$} & \multirow[b]{2}{*}{ Mean cell volum } \\
\hline IA & FA & & & & & \\
\hline \multicolumn{7}{|c|}{ Hospitalizations } \\
\hline Yes & Yes & 50 & $8.7 \pm 3.8$ & $2.8 \pm 0.4$ & $8.5 \pm 0.8$ & $90.5 \pm 13.3$ \\
\hline Yes & No & 47 & $8.9 \pm 4.0$ & $2.9 \pm 0.4$ & $8.6 \pm 0.9$ & $86.9 \pm 10.6$ \\
\hline No & Yes & 14 & $9.0 \pm 5.3$ & $2.8 \pm 0.5$ & $8.6 \pm 0.9$ & $85.2 \pm 11.4$ \\
\hline No & No & $\begin{array}{r}23 \\
134\end{array}$ & $13.8 \pm 5.3$ & $2.7 \pm 0.4$ & $9.0 \pm 1.1$ & $87.4 \pm 10.9$ \\
\hline Sig level & & & $\mathrm{p}<0.001$ & $p=0.38$ & $\mathrm{p}=0.24$ & $\mathrm{p}=0.34$ \\
\hline \multicolumn{7}{|c|}{ Transfusions } \\
\hline Yes & Yes & 13 & $7.4 \pm 3.4$ & $2.9 \pm 0.5$ & $8.0 \pm 0.6$ & $95.1 \pm 11.3$ \\
\hline Yes & No & 53 & $9.0 \pm 4.9$ & $2.9 \pm 0.4$ & $8.5 \pm 0.9$ & $89.0 \pm 13.5$ \\
\hline No & Yes & 9 & $7.4 \pm 3.8$ & $2.8 \pm 0.5$ & $8.8 \pm 0.7$ & $88.0 \pm 8.2$ \\
\hline No & No & $\begin{array}{r}64 \\
139\end{array}$ & $11.0 \pm 4.4$ & $2,8 \pm 0.4$ & $8.8 \pm 0.9$ & $86.3 \pm 10.3$ \\
\hline Sig level & & & $p=0.01$ & $p=0.58$ & $p=0.03$ & $p=0.09$ \\
\hline \multicolumn{7}{|c|}{ Pain crises } \\
\hline Yes & Yes & 74 & $9.1 \pm 3.8$ & $2.8 \pm 0.4$ & $8.6 \pm 0.8$ & $89.6 \pm 12.9$ \\
\hline Yes & No & 16 & $8.8 \pm 5.5$ & $3.0 \pm 0.4$ & $8.5 \pm 1.1$ & $86.2 \pm 9.3$ \\
\hline No & Yes & 16 & $11.3 \pm 4.7$ & $2.7 \pm 0.4$ & $8.9 \pm 1.0$ & $85.7 \pm 8.3$ \\
\hline No & No & $\begin{array}{r}12 \\
118\end{array}$ & $11.4 \pm 7.2$ & $2.7 \pm 0.5$ & $8.3 \pm 1.1$ & $89.0 \pm 15.2$ \\
\hline Sig level & & & $\mathrm{p}=0.17$ & $p=0.12$ & $p=0.24$ & $p=0.57$ \\
\hline
\end{tabular}

*Defined by whether a patient did or did not experience an event that measures degree of severity (a hospitalization, a transfusion, or a pain crisis) evaluated in the period prior to initial assessment or in the period of follow-up.

initial assessment and hospitalization status during the 3-year follow-up period. Similarly, the association between an individual's transfusion status at initial assessment and at the second clinical assessment was also not significantly different from zero (Kappa, $0.08 \pm 0.06$ ). However, there was a stronger association between an individual's pain crisis status at initial assessment and at the second clinical assessment during follow-up (Kappa, $0.25 \pm 0.10$ ). Of the 90 individuals who had a pain crisis before enrolling into the center, $74(82 \%)$ also had a pain crisis at the second clinical assessment, while of the 28 individuals who did not have a pain crisis before enrolling in the center, $16(57 \%)$ had a pain crisis at the second clinical assessment.

There were no significant differences among the 4 severity classes of each clinical measure for 1) the proportion of males and females, 2) the length of the second clinical assessment, and 3) the length of time between a patient's initial assessment and the second clinical assessment (data not shown). For the hospitalization measure only, there was a small (but statistically significant) difference among strata for the mean number of clinical visits during the follow-up period. For all 3 clinical measures, there were highly significant differences among the strata for the average age at initial assessment and average age of the patient for the period of time followed in the 3-year follow-up. Those reporting no event at the initial assessment were younger in each case. 
TABLE III. Estimates of the Change in the Odds of Experiencing the Event Compared to the Odds of Not Experiencing the Event (odds ratio = OR/SD) for Each Unit Change in the SD of the Predictor Variables, \%HbF and Age

\begin{tabular}{|c|c|c|c|}
\hline Outcome $^{\mathrm{a}}(\mathrm{N})$ & Variable & $\mathrm{OR} / \mathrm{SD}$ & $95 \% \mathrm{CI}^{\mathrm{b}}$ \\
\hline \multicolumn{4}{|l|}{ Hospitalizations } \\
\hline \multirow[t]{2}{*}{$2(50)$ vs $0(23)$} & $\% \mathrm{HbF}^{\mathrm{c}}$ & $3.58 *$ & $1.18-7.28$ \\
\hline & Age & 1.79 & $0.43-3.42$ \\
\hline \multirow[t]{2}{*}{$1(51)$ vs $0(23)$} & $\% \mathrm{HbF}$ & $2.67^{*}$ & $1.53-4.63$ \\
\hline & Age & 1.06 & $0.60-1.88$ \\
\hline \multicolumn{4}{|l|}{ Transfusions } \\
\hline \multirow[t]{2}{*}{$2(13)$ vs $0(64)$} & $\% \mathrm{HbF}$ & $5.56^{*}$ & $1.67-18.96$ \\
\hline & Age & $3.44 *$ & $1.30-9.08$ \\
\hline \multirow[t]{2}{*}{$1(62)$ vs $0(64)$} & $\% \mathbf{H b F}$ & $1.75^{*}$ & $1.16-2.64$ \\
\hline & Age & $1.69 *$ & $1.13-2.53$ \\
\hline \multicolumn{4}{|l|}{ Pain crisis } \\
\hline \multirow[t]{2}{*}{$2(74)$ vs $0(12)$} & $\% \mathrm{HbF}$ & 1.67 & $0.89-3.07$ \\
\hline & Age & 1.62 & $0.85-3.08$ \\
\hline \multirow[t]{2}{*}{$1(32)$ vs $0(12)$} & $\% \mathrm{HbF}$ & 1.21 & $0.70-2.13$ \\
\hline & Age & 1.15 & $0.58-2.29$ \\
\hline
\end{tabular}

*Significantly different from one at 0.05 level of probability.

a, Event both at initial assessment and during the follow-up period; 1 , an event for either of the clinical assessments; and 0 , event did not occur.

${ }^{b} \mathrm{CI}$, confidence interval on OR/SD.

${ }^{\mathrm{c}}$ Radial immunodiffusion assay for $\mathrm{HbF}$.

The frequencies of the 4 severity classes of the 3 severity measures presented in Table I did not occur as independent events. There was a highly significant correlation between an individual's hospitalization classification and transfusion classification (Goodman-Kruskal gamma (GK gamma), $0.46 \pm 0.08$ ) and between an individual's hospitalization classification and pain crisis classification (GK gamma, $0.67 \pm 0.07$ ). The correlation between transfusions and pain was also significantly different from zero, but the estimate of association was lower than for the other 2 pairwise comparisons (GK gamma, $0.35 \pm 0.12$ ).

The mean values of the age-adjusted hematological variables are presented by severity class in Table II for each clinical measure. Age-adjusted mean \% HbF levels were significantly different among the severity classifications of the hospitalization and transfusion measures. Scheffe's contrasts [Neter and Wasserman, 1974] detected significantly elevated $\% \mathrm{HbF}$ levels for individuals in the category that had not been hospitalized $(n=23, \% \mathrm{HbF} 13.58)$ and in the category that did not report a transfusion $(n=64, \% \mathrm{HbF} 11.0)$. Mean $\% \mathrm{HbF}$ levels were not significantly different among the other 3 strata for either of these variables, nor were they significantly different among the 4 pain crises strata. Mean $\mathrm{Hb}$ levels were significantly different among severity classes based on transfusion status $(\mathrm{p}<0.05)$ but not for hospitalizations nor for pain crises. Neither $\% \mathrm{HbA}_{2}$ nor $\mathrm{MCV}$ were significantly different among strata for any of the clinical variables considered.

The results of the stepwise logistic regression analysis used to evaluate the magnitude of the associations between 6 independent variables (age, sex, \% $\mathrm{HbF}$, $\% \mathrm{HbA}_{2}, \% \mathrm{Hb}$, and $\mathrm{MCV}$ ) and the 4 severity classes of each clinical measure are presented in Table III. For the 3 separate analyses, individuals who were not hospi- 
TABLE IV. Average \%HbF and Age in Years for Individuals Classified According to Whether They Reported Hospitalization and a Transfusion (2 yes), Hospitalized or a Transfusion (1 yes), or Neither (0 yes) at the Initial Assessment (Columns) and During the Follow-up (Rows)

\begin{tabular}{|c|c|c|c|c|c|}
\hline \multirow[b]{2}{*}{ Follow-up } & \multirow[b]{2}{*}{ Variable } & \multicolumn{4}{|c|}{ Initial assessment } \\
\hline & & 2 Yes & 1 Yes & 0 Yes & Overall \\
\hline \multirow[t]{3}{*}{2 Yes } & $\% \mathrm{HbF}$ & $7.59 \pm 3.5^{\mathrm{a}}$ & $8.73 \pm 4.3$ & $6.49 \pm 4.6$ & $7.54 \pm 3.7$ \\
\hline & $\mathrm{N}$ & 12 & 3 & 4 & 19 \\
\hline & Age & 14.2 & 9.5 & 9.2 & \\
\hline \multirow[t]{3}{*}{1 Yes } & $\% \mathrm{HbF}$ & $8.80 \pm 4.1$ & $9.52 \pm 3.3$ & $9.68 \pm 5.6$ & $9.20 \pm 4.1$ \\
\hline & $\mathrm{N}$ & 23 & 15 & 9 & 47 \\
\hline & Age & 13.5 & 10.2 & 9.2 & \\
\hline \multirow[t]{4}{*}{0 Yes } & $\% \mathrm{HbF}$ & $7.87 \pm 4.5$ & $11.11 \pm 4.3$ & $13.61 \pm 4.9$ & $10.62 \pm 5.1$ \\
\hline & $\mathbf{N}$ & 25 & 24 & 19 & 68 \\
\hline & Age & 13.5 & 11.5 & 11.4 & \\
\hline & & $8.17 \pm 4.2$ & $10.37 \pm 4.0$ & $11.61 \pm 5.6$ & $9.68 \pm 4.7$ \\
\hline Overall & $\begin{array}{l}\% \mathrm{HbF} \\
\mathrm{N}\end{array}$ & 60 & 42 & 32 & 134 \\
\hline
\end{tabular}

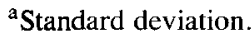

TABLE V. Estimates of the Change in the Odds of Experiencing the Combined Hospitalization and Transfusion Events Compared to the Odds of Not Experiencing the Event (odds ratio $=O R$ / SD) for Each Unit Change in the SD of the Predictor Variables, \%HbF and Age

\begin{tabular}{lccc}
\hline Outcome $^{\mathrm{a}}$ & Variable & OR/SD & $95 \% \mathrm{CI}^{\mathrm{b}}$ \\
\hline $3-4(33)$ vs 0 (19) & \%HbF & 4.67 & $1.84-11.18$ \\
& Age & 3.07 & $1.25-7.54$ \\
$1-2(77)$ vs 0 (19) & $\% \mathrm{HbF}$ & 2.32 & $1.27-4.04$ \\
& Age & 1.03 & $0.57-1.88$ \\
\hline
\end{tabular}

${ }^{a}$ The number of reports of hospitalization and/or transfusions at initial assessment and during the followup period, eg, $4=$ both hospitalization and transfusion occurred at initial assessment and during the follow-up period; and $\mathbf{0}=$ neither hospitalization nor transfusion occurred at the initial assessment and during the follow-up period.

${ }^{b} \mathrm{CI}$, Confidence interval on OR/SD.

talized, did not have a transfusion, or did not have a pain crisis at both initial assessment and at the second clinical assessment were used as the baseline group for the comparisons. Of the 6 independent variables considered, only \% HbF and age were significant predictors of any of these severity measures. A decrease in $\% \mathrm{HbF}$ levels of one SD (4.76\%) was associated with $3.58(95 \% \mathrm{CI}=1.18-7.28)$ fold greater odds of being hospitalized at both evaluations, and 2.67 fold greater odds of being hospitalized at one evaluation, compared to the baseline group. Similarly, a decrease in \% $\mathrm{HbF}$ levels of one SD was associated with 5.56 fold greater odds of having a transfusion at both evaluations and 1.75 fold greater odds of having a transfusion at one evaluation, compared to the baseline group. Age was a significant predictor of an individual's transfusion status but not of hospitalization nor of pain crises. Neither age nor $\% \mathrm{HbF}$ were significant predictors of pain crises in this sample.

In Table IV, we present the mean $\% \mathrm{HbF}$ values and mean age for severity classifications based on hospitalization and transfusions. Nine strata were defined, corresponding to the presence or absence of hospitalizations and transfusions at initial assessment (both present, one present, or none present) and the presence or absence 
of these severity measures at the second clinical assessment. Mean $\% \mathrm{HbF}$ and age were both significantly different among the 9 strata $(\mathrm{p}<0.001$ for $\% \mathrm{HbF}$ and $\mathrm{p}<$ 0.002 for age). Mean $\% \mathrm{HbF}$ levels were relatively low for the group that were hospitalized and transfused at both initial assessment and at the second clinical assessment (4 total events, mean \% HbF 7.59) and highest for the group that were not hospitalized nor transfused at either evaluation ( 0 total events, mean \%HbF 13.61).

In general, individuals who had the same number of total events (the number of events ranged from 0 to 4 ) had similar $\% \mathrm{HbF}$ levels, regardless of whether the events occurred prior to initial assessment or at the second clinical assessment. For example, mean $\% \mathrm{HbF}$ levels were very similar in those individuals who had 2 events at initial assessment and one event at the second clinical evaluation (\% $\mathrm{HbF} 8.80$ ), as compared to those individuals who had one event at initial assessment and 2 events at the second clinical evaluation (\% HbF 8.73). However, there was a significant difference in mean age among those individuals who had their events at initial assessment, as compared to those individuals who had their events at the second clinical evaluation. In general, individuals who were hospitalized and/or transfused at initial assessment but not at the second clinical evaluation were significantly older (13.5 and 11.5 years) than the individuals who were hospitalized and/or transfused at the second clinical evaluation but not at initial assessment ( 9.2 years).

In Table $\mathrm{V}$, we present results of the stepwise logistic regression analysis evaluating the magnitude of the association between age and $\% \mathrm{HbF}$ and the combined hospital, transfusion measure. A decrease in \% $\mathrm{HbF}$ levels of one SD was associated with 4.67 fold greater odds of having 3 or 4 events and 2.32 fold greater odds of having 1 or 2 events, compared to those having no events. An increasing age was also associated with increasing odds of having 3 or 4 events, compared to those having no events (odds ratio $=3.07$ ) but not with the odds of having 1 or 2 vs no events.

\section{DISCUSSION}

The most significant result of this study is the demonstration that $\% \mathrm{HbF}$ is a strong predictor of hospitalizations and transfusions in children with sickle cell anemia (Tables III, IV, V). Mean \% HbF levels were $6.02 \%$ lower for the individuals who had at least one hospitalization and one transfusion at both initial assessment and at the second clinical assessment (mean \% HbF 7.59), as compared to those individuals who were not hospitalized nor transfused at either of these evaluations (mean $\% \mathrm{HbF}$ 13.61).

A number of investigators have studied the association between $\% \mathrm{HbF}$ and disease severity, with conflicting results. It has been reported that $\% \mathrm{HbF}$ is elevated in mild sickle cell disease in the Middle East [Ali, 1970; Perrine et al, 1972; Haghshenass et al, 1977]. Two studies in Jamaica also found an association between increased \% $\mathrm{HbF}$ and reduced severity. Serjeant and Ashcroft [1972] found elevated levels of $\% \mathrm{HbF}$ associated with improved skeletal maturation, and Stevens et al [1981] found that \% HbF levels measured at age 6 months were significantly decreased in children manifesting early palpable splenomegaly, dactylitis, and acute splenic sequestration or death during the first 2 years of life. However, 2 studies in the United States have failed to find these associations between $\% \mathrm{HbF}$ and disease severity. Steinberg et al [1973] compared 21 patients manifesting mild sickle cell disease (aged 18-56) with 12 severely affected patients. In their study, a severity score was assigned 
to each patient based on the occurrence of pain crises, infections, transfusions, neurologic signs, orthopedic defects, leg ulcers, and employment or activity status. There was no difference in $\% \mathrm{HbF}$ levels between the mild and severe groups. Powars et al [1980] examined the relationship between 7 clinical indicators of morbidity (sickle cell crises, acute chest syndrome, hospital admissions, aseptic necrosis, meningitis/septicemia, and death) and 7 hematological measures $(\mathrm{Hb}, \mathrm{HCT}$, absolute $\mathrm{HbF}, \% \mathrm{HbF}, \% \mathrm{HbA}_{2}, \mathrm{MCV}$, and $\mathrm{MCHC}$ ) collected on 214 patients whose mean age was 19.4 years. The only statistically significant finding was an increased occurrence of stroke with lower levels of \% $\mathrm{HbF}$. \% $\mathrm{HbF}$ levels (or any of the other hematological variables) were not significantly associated with any of the other severity measures considered.

The results of the different studies are not comparable because there are important differences in the age distribution among samples and in the measures of severity analyzed. In this population of affected children we have shown a negative regression of $\mathrm{HbF}$ on age, the proportion of $\mathrm{HbF}$ falling from $12 \%$ at age 3 to approximately $6 \%$ at age 20 [Odenheimer et al, 1983]. In this study the proportion of $\mathrm{HbF}$ of each individual was corrected by a standard statistical technique to remove the effect of varying age. Thus, the difference between the effects of $\mathrm{HbF}$ on clinical manifestations in this study and those reported by Steinberg et. al [1973] and Powars et al [1980] may be due to the different age ranges involved and the procedures used to adjust for age variability. Similar corrections for age in future studies will facilitate comparison with the results of our study.

The strong relationship between $\% \mathrm{HbF}$ and disease that we found would not have been identified if we had limited our data to those collected at either initial assessment or at the second clinical assessment. For example, we identified one group of individuals who were hospitalized and transfused at initial assessment that did not have either of these events at the second clinical assessment. These individuals (Table IV) had a mean $\% \mathrm{HbF}$ level of $7.8 \%$ and a mean age of 13.5. Thus, these individuals have $\% \mathrm{HbF}$ levels that are hypothesized to be associated with severe disease, even though all were disease free at the second clinical assessment. A possible explanation for this finding is that these individuals had entered the quiescent period of adolescence or early adulthood at the second clinical assessment and no longer experienced severe complications of the disease. Alternatively, the change in the number of hospitalizations may reflect the influence of care at the Center upon use of hospital facilities. We identified a second group of individuals who were not hospitalized nor transfused at initial assessment but who did have both of these events at the second clinical assessment. These individuals (Table IV) had a mean \% HbF level of $6.49 \%$ and a mean age of 9.2 years. Thus, these patients also had \% HbF levels that are hypothesized to be associated with severe disease, even though all were relatively mild at initial assessment. A possible explanation for this finding is that these individuals were too young at initial assessment (mean age at initial assessment, 2.7) to develop severe complications of the disease. Alternatively, this may be a subset for which severity increases after childhood.

\%HbF drops with increasing age, at least until age 35 [Davis, 1976; Rucknagel et al, 1979; Pembrey et al, 1978]. In our sample, age accounted for approximately $25 \%$ of the variability in $\% \mathrm{HbF}$. However, in a previous report we demonstrated that age-adjusted $\% \mathrm{HbF}$ levels are very stable over time [Odenheimer et al, 1984]. The correlation between 2 measurements taken an average of 32 months apart was over 
0.90. The high degree of tracking reported previously and the strong relationship between $\% \mathrm{HbF}$ and severity reported here suggests that a single $\% \mathrm{HbF}$ measurement may be useful in predicting aspects of the clinical course of children with sickle cell anemia, provided it is age corrected and provided the subject is in a steady state and the measurement is not during an acute hyperhemolytic episode. The lack of association of pain crises with hospitalization and transfusion in these data was surprising in view of the importance of pain in the decision to hospitalize patients.

\section{ACKNOWLEDGMENTS} 20964.

This study was supported by NIH Grant HL-16008 and NIH Grant 5-R01-AM-

\section{REFERENCES}

Ali SA (1970): Milder variant of sickle cell disease in Arabs in Kuwait associated with unusually high level of foetal haemoglobin. Br J Haematol 19:613-619.

Chudwin DS, Rucknagel DL (1975): Immunological quantification of hemoglobins $\mathrm{F}$ and $\mathrm{A}_{2}$. Clin Chim Acta 50:413-418.

Davis LR (1976): Changing blood picture in sickle-cell anemia from shortly after birth to adolescence. J Clin Pathol 29:898-901.

Fleiss JL (1981): "Statistical Methods for Rates and Proportions," 2nd Ed. New York: John Wiley \& Sons, pp 117-133.

Goodman LA, Kruskal WH (1972): Measures of association for cross classification IV. J Am Stat Assoc 67:415-421.

Haghshenass M, Ismail-Beigi F, Clegg JB, Weatherall DJ (1977): Mild sickle cell anemia in Iran associated with high levels of fetal hemoglobin. J Med Genet 14:168-171.

Kleinbaum DG, Kupper LL, Murgenstern H (1982): "Epidemiologic Research: Principles and Quantitative Methods." Belmont, CA: Lifetime Learning Publications, pp 420-491.

Neter J, Wasserman W (1974): "Applied Linear Statistical Models." Homewood, IL: Richard D. Irwin, p 262 .

Odenheimer DJ, Whitten CF, Rucknagel DL, Sarnaik SA, Sing CF (1983): Heterogeneity of sickle cell anemia based on a profile of hematological variables. Am J Hum Genet 35:1224-1240.

Odenheimer DJ, Whitten CF, Rucknagel DA, Sarnaik SA, Sing CF (1984): Stability over time of hematological variables in 197 children with sickle cell anemia. Am J Med Genet 18:461-470.

Pembrey ME, Wood WG, Weatherall DJ, Perrine RP (1978): Foetal haemoglobin production and the sickle gene in the oases of eastern Saudi Arabia. Br J Haematol 40:415-429.

Perrine RP, Brown MJ, Weatherall DJ, Clegg JB, May A (1972): Benign sickle cell anaemia. Lancet 2:1163-1167.

Powars DR, Schroeder WA, Weiss JN, Chan LS, Azen SP (1980): Lack of influence of fetal hemoglobin levels of erythrocyte indices on the severity of sickle cell anemia. J Clin Invest 65:732-739.

Rucknagel DL, Hanash SM, Sing CF, Winter WP, Whitten CF, Prasad AS (1979): Age and sex effects on hemoglobin $\mathbf{F}$ in sickle cell anemia. In Stamatoyannopoulos G, Nienhuis A (eds): "Cellular and Molecular Regulation of Hemoglobin Switching." New York: Grune and Stratton, pp 107117.

Serjeant GR, Ashcroft MT (1972): Delayed skeletal maturation in sickle cell anemia in Jamaica. Johns Hopkins Med J 132:95-102.

Steinberg MH, Dreiling BJ, Morrison FS, Neecheles TF (1973): Mild sickle cell disease. JAMA 224:317-321.

Stevens MCG, Hayes RJ, Vaisya S, Serjeant GR (1981): Fetal hemoglobin and clinical severity of homozygous sickle cell disease in early childhood. J Pediatr 98:37-41.

Warth JA, Rucknagel DL (1983): The increasing complexity of sickle cell anemia. In Brown EB (ed): "Progress in Hematology, Vol XIII." New York: Grune and Stratton, Inc., pp 25-47. 